Contents List available at RAZI Publishing Acta Scientifica Malaysia (ASM)

Journal Homepage: http://www.razipublishing.com/journals/acta-scientificamalaysia-asm/archives/

https://doi.org/10.26480/asm.01.2017.11.13

\title{
DETERMINATION OF POLYCHLORINATED BIPHENILS IN THE SOIL, ATMOSPHERIC DEPOSITION AND BIOINDICATOR SAMPLES IN THE MERIC-ERGENE RIVER BASIN, TURKEY
}

\author{
Asude HANEDAR ${ }^{1 *}$, Elçin GÜNEŞ ${ }^{1}$, Gül KAYKIOĞLU1 ${ }^{1}$ Evren CABİ ${ }^{2}$ \\ ${ }^{1}$ Namik Kemal University Corlu Engineering Faculty, Environmental Engineering Department, Corlu-TEKiRDAG
}

${ }^{2}$ Namik Kemal University, Faculty of Arts and Sciences, Biology Department, Corlu-TEKIRDAG *Corresponding Author: Namik Kemal University Corlu Engineering Faculty Environmental Engineering Department, Corlu, Tekirdag, Turkey e-mail:ahanedar@nku.edu.tr Tel: +90282 2502381

This is an open access article distributed under the Creative Commons Attribution License, which permits unrestricted use, distribution, and reproduction in any medium, provided the original work is properly cited.

\section{ARTICLE DETAILS}

\section{Article history:}

Received 12 August 2016 Accepted 12 December 2016

Available online 20 January 2017

Keywords:

Polychlorinated Bioindicators, Lifetime Cancer Risk, MericErgene Basin

\section{ABSTRACT}

The Meric-Ergene Basin, located on the north-western part of Turkey, begins with the Istanbul provincial border in the east and covers the border area with Bulgaria and Greece borders in the west. The industry developed at a rapid race, especially in the last fifty years, despite the importance of agriculture in the basin. In the study, 15 types of Polychlorinated Biphenils (PCBs) were determined in 4 regions of in an intense industrialized area, industrial+residential area, an agricultural area and a background area in total of 12 points, in 2014-2015, representing 4 seasons, in soil, lichen, pine needles and bulk samples, in the basin.

In the study, spatial and seasonal changes in PCBs concentrations were set forth and "Incremental Lifetime Cancer Risk" were conducted. According to the results, increasing PCB values were observed in industrial areas and in soil samples. Generally heavier PCB species more abundant in the sampling area. PCB concentrations reached the highest values for all matrixes in the 2014 Spring and 2015 winter. According to the results of ILCR study, "Cancer Increase Rate" due to the PCB concentration was found to be over $10^{-4}$ and cancer risk assessment studies are needed in the area.

\section{INTRODUCTION}

Polychlorinated biphenils (PCBs) are a group of aromatic and synthetic compounds and have no natural sources. Due to their physical and chemical properties they are widely distributed in the environment and accumulated through the food web up to and including humans and influence human health [1]. PCBs were extensively used in various industrial applications like capacitors, transformers, and paints over the period of 1930-1975. However, their production was discontinued and their use was banned in many countries several decades ago. PCBs are emitted into the environment from PCB containing wastes, open burning, waste incineration, evaporation from PCB containing products and contaminated surfaces, and accidental spills to soil [2]. Soil and biological monitors have been used to evaluate environmental contamination, assessing the transfer of compounds from the natural environment to humans [3]. The Meric-Ergene River Basin, which is the area where the study is carried out, is located in the north-west of Turkey. $70 \%$ of the river basin consists of agricultural areas. Although agriculture maintains its importance in the region, the basin has faced to rapid development of the industry. There are approximately 1,300 industrial facilities in the textile, chemical, metal-automotive and food sectors, in the basin. In this study, 15 PCBs were sampled in 12 sampling points in soil, lichen and pine needle samples and in the total atmospheric deposition samples in the basin. The data obtained were evaluated on the basis of spatial and temporal variations, and cancer risk evaluation was conducted to the results.

\section{Material and Methods}

Study Area: In this study, 15 PCBs were measured in 4 periods representing the 4 seasons for 1 year (May 2014, July 2014, October 2014, February 2015 ) at 3 sampling points (at a total of 12 points) in 4 different regions consisting of industrial area (Ind), industrial+residential area (IndR), agricultural area (Agr) and background (Bg). PCB concentrations were determined in soil, lichen and pine needle samples and in the total atmospheric deposition samples. The characteristics of the sampling points are given in Table 1.

Sampling: Soil samples were taken from 0-5 cm depth of the surface to characterize the surface soil using the multiple sampling method Lichen samples of Xanthoria parietina species and pine needles samples of Pinus and Quercus taxa were sampled in the region surrounding the sampling point. Total deposition sampling equipment consisting of 60 $\mathrm{cm}$ stainless steel funnel and 20 liter glass bottle which was designed to be placed about $1.5 \mathrm{~m}$ height was kept at the sampling point for 2 weeks. Analysis Procedure: For pre-treatment procedure, soil, lichen or pine needle samples were weighed and dried with lyophilizator, and they were subjected to ultrasonic extraction. Clean up stage was made with alumina-silicic acid column [4]. The samples analyzed in GC-MS. Total deposition samples extracted by liquid-liquid extraction with hexane. The blank sample tests were conducted for each sample set. The instrumental detection limit and system performance measurements were conducted for the GC-MS device. Recovery of PCBs was found in $63-92 \%$ for all samples.

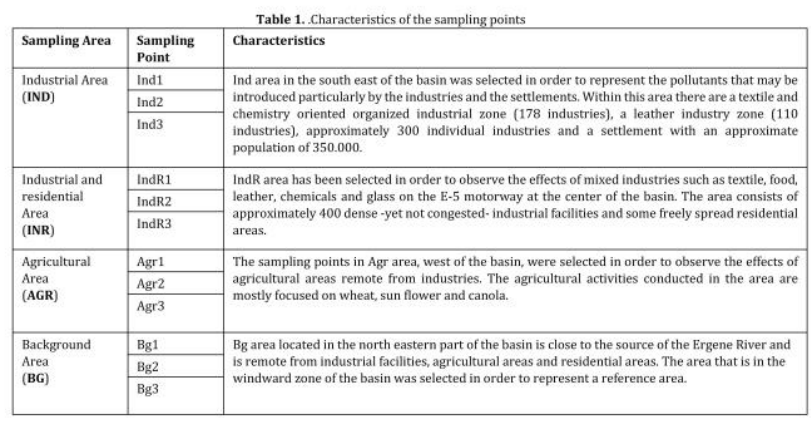

\section{Results}


Descriptive statistics of the total PCB concentration values are presented in Table 2 . As it is seen, the total PCB values varied between $10-63 \mathrm{ng} / \mathrm{g}$ for soil samples at all sampling points, and the highest values were determined in Ind areas. PCB values varied between 10-68 $\mathrm{ng} / \mathrm{g}$ for lichen samples, and the highest concentrations were measured in the IndR area. It was measured between 11-33 ng/g for pine needle samples, and the highest values were determined in the Agr area. The values varied between $0-144 \mathrm{ng} / \mathrm{m}^{2}$-day for the total deposition samples, and the highest values were measured in the IndR area. For the total PCB values, generally higher values were obtained in the soil samples and the lowest values were observed for pine needle samples. In general, the seasons in which the highest values are obtained for each matrix are Spring 2014 and Winter 2015.

PCB species are also evaluated according to their homolog groups. In Table 3, distributions of homolog groups of measured PCBs are given. The hepta and octa groups were evaluated together. Spatial distributions of determined homolog groups of PCBs are given in Figure 1. In general, heavy PCB species are predominantly determined for all sampling matrices. Maximum concentrations were measured for heptaocta PCBs in all sampling areas Given the distribution of weights, it can be said that the heavier species are more abundant in industrial areas and the light species are dominant in background areas.
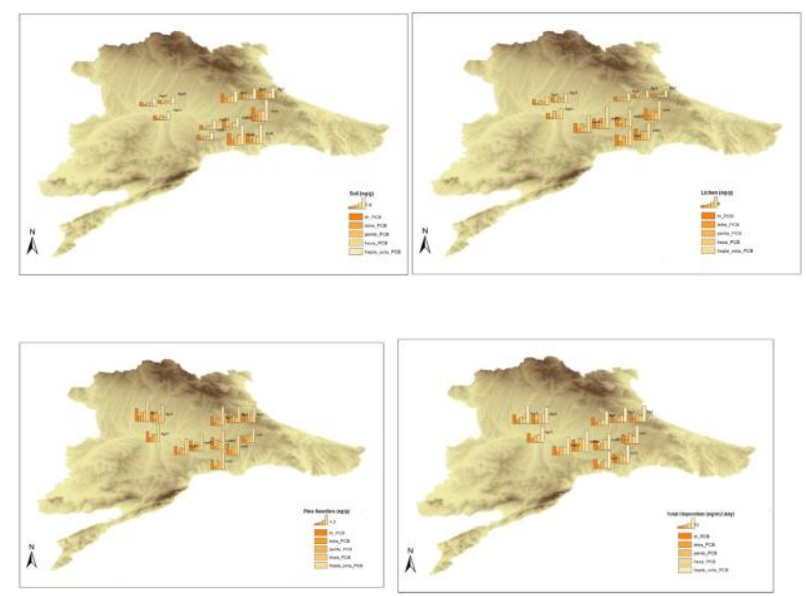

\begin{tabular}{|c|c|c|c|c|c|}
\hline \multirow{3}{*}{ Sampling Area } & \multirow{3}{*}{ Statistics } & \multicolumn{4}{|c|}{$\Sigma_{15}$ PCB } \\
\hline & & Soil & Lichen & $\begin{array}{l}\text { Pine } \\
\text { Neddles }\end{array}$ & \multirow{2}{*}{$\begin{array}{l}\begin{array}{l}\text { Total } \\
\text { Deposition }\end{array} \\
\mathrm{ng} / \mathrm{m}^{2} \text {-day }\end{array}$} \\
\hline & & \multicolumn{3}{|c|}{$\mathrm{ng} / \mathrm{g}(\mathrm{dw})$} & \\
\hline \multirow[t]{5}{*}{ Ind $\mathrm{n}=12$} & Max. & 62,85 & 48,97 & 25,24 & 75,16 \\
\hline & Min. & 19,34 & 17,06 & 14,21 & 44,01 \\
\hline & Median & 34,77 & 20,53 & 18,35 & 48,28 \\
\hline & Average & 37,2 & 27,47 & 18,93 & 54,02 \\
\hline & Std. Dev. & 15,55 & 12,65 & 3,5 & 11,09 \\
\hline \multirow[t]{5}{*}{ IndR $n=12$} & Max. & 42,19 & 68,08 & 32,69 & 144,44 \\
\hline & Min. & 10,39 & 10,03 & 13,62 & 41,08 \\
\hline & Median & 13,8 & 22,64 & 16,24 & 47,50 \\
\hline & Average & 16,48 & 25,94 & 18,65 & 57,93 \\
\hline & Std. Dev. & 8,58 & 15,84 & 5,7 & 28,45 \\
\hline \multirow[t]{5}{*}{ Agr $n=12$} & Max. & 16,12 & 18,95 & 32,25 & 87,85 \\
\hline & Min. & 9,98 & 10,27 & 13,45 & 41,39 \\
\hline & Median & 11,95 & 13,23 & 16,62 & 44,90 \\
\hline & Average & 12,52 & 13,29 & 20,71 & 50,06 \\
\hline & Std. Dev. & 2,09 & 2,57 & 8,08 & 13,04 \\
\hline \multirow[t]{5}{*}{ Bg $n=12$} & Max. & 39,98 & 15,68 & 32,82 & 61,80 \\
\hline & Min. & 10,96 & 6,78 & 11,35 & 0,00 \\
\hline & Median & 22,97 & 11,57 & 13,56 & 39,78 \\
\hline & Average & 23,86 & 11,24 & 17,79 & 39,62 \\
\hline & Std. Dev. & 9,43 & 3,1 & 7,84 & 14,70 \\
\hline
\end{tabular}

*Bolds are the highest values.

\begin{tabular}{|l|l|l|}
\multicolumn{2}{c|}{ Table 3. Homologue Groups of PCBs } \\
\hline Homologue Groups & Chlorine Number & PCB species \\
\hline Tri-PCBs & 3 Chlorines & PCB118, PCB20, PCB28, PCB31 \\
\hline Tetra-PCBs & 4 Chlorines & PCB52, PCB44 \\
\hline Penta-PCBs & 5 Chlorines & PCB101, PCB105, PCB118 \\
\hline Hexa-PCBs & 6 Chlorines & PCB138, PCB149, PCB153 \\
\hline Hepta-0cta PCBs & 7 and 8 Chlorines & PCB170-, PCB180, PCB194 \\
\hline
\end{tabular}

3.1. Cancer Risk Calculation: In the study Incremental Lifetime Cancer Risk (ILCR) were used for evaluation cancer risk according to USEPA methods. ILCR values were calculated for direct ingestion, dermal contact and inhalation routes by these formulas $[5,6,7]$.

$$
\begin{aligned}
& \mathrm{ILCRS}_{\text {Ingestion }}=\frac{\mathrm{CS} \times\left(\mathrm{CSF}_{\text {Ingestion }} \times \sqrt[3]{(\mathrm{BW} / 70)}\right) \times I R_{\text {soil }} \times \mathrm{EF} \times \mathrm{ED}}{\mathrm{BW} \times \mathrm{AT} \times 10^{6}} \\
& \mathrm{ILCRS}_{\text {Dermal }}=\frac{\mathrm{CS} \times\left(\mathrm{CSF}_{\text {Dermal }} \times \sqrt[3]{(\mathrm{BW} / 70)}\right) \times \mathrm{SA} \times \mathrm{AF} \times \mathrm{ABS} \times \mathrm{EF} \times \mathrm{ED}}{\mathrm{BW} \times \mathrm{AT} \times 10^{6}} \\
& \mathrm{ILCRS}_{\text {Inhalation }}=\frac{\mathrm{CS} \times\left(\mathrm{CSF}_{\text {Inhalation }} \times \sqrt[3]{(\mathrm{BW} / 70)}\right) \times I R_{\text {air }} \times \mathrm{EF} \times \mathrm{ED}}{\mathrm{BW} \times \mathrm{AT} \times \mathrm{PEF}}
\end{aligned}
$$

The determination of carcinogenic slope factor was based on the cancer-causing ability of total

PCBs. $\mathrm{CSF}_{\text {Ingestion, }} \mathrm{CSF}_{\text {Dermal, }}$ and $\mathrm{CSF}_{\text {Inhalation of total PCBs were 2, 2,22 }}$ and $2\left(\mathrm{mg} \mathrm{kg}^{-1} \mathrm{~d}^{-1}\right)^{-1}$, respectively $[8,9,10]$. The risks for children and adults were calculated separately. The total risks were the sum of risks associated with each exposure route. The variables used in the exposure calculation are given in Table 4. Calculated ILCR values are

\begin{tabular}{|c|c|c|c|c|c|c|}
\hline \multirow[b]{2}{*}{$\begin{array}{l}\text { Exposure } \\
\text { pathways }\end{array}$} & \multicolumn{3}{|c|}{ Children } & \multicolumn{3}{|c|}{ Adult } \\
\hline & Ind & IndR & Agr & Ind & IndR & Agr \\
\hline Direct ingestion & $1,62636 \mathrm{E}-08$ & 7,20495E-09 & $5,47366 \mathrm{E}-09$ & $1,12949 \mathrm{E}-08$ & $5,00375 \mathrm{E}-09$ & $3,80139 \mathrm{E}-09$ \\
\hline Dermal contact & 3,24947E-09 & 1,43955E-09 & $1,09364 \mathrm{E}-09$ & $1,25373 \mathrm{E}-08$ & $5,55416 \mathrm{E}-09$ & $4,21955 \mathrm{E}-09$ \\
\hline Inhalation & 0,000308023 & 0,000136457 & 0,000103668 & 0,001711344 & 0,000758144 & 0,000575968 \\
\hline Total & $3,1 \times 10^{-4}$ & $1,4 \times 10^{-4}$ & $1,0 \times 10^{-4}$ & $1,7 \times 10^{3}$ & $7,6 \times 10^{-4}$ & $5,8 \times 10^{-4}$ \\
\hline
\end{tabular}
given in Table 5 .

Table 4. Parameters used in the ILCR assessment [7]
\begin{tabular}{|l|l|c|c|}
\hline Exposure variable & Unit & Child & Adult \\
\hline Body weight (BW) & $\mathrm{kg}$ & 15 & 60 \\
\hline Exposure frequency (EF) & day/year & 350 & 350 \\
\hline Exposure duration (ED) & year & 2 & 7 \\
\hline Inhalation rate (IRair) & $\mathrm{m}^{3} / \mathrm{day}$ & 5 & 20 \\
\hline Soil intake rate $(\mathrm{IR}$ soil) & $\mathrm{mg} / \mathrm{day}$ & 200 & 100 \\
\hline Dermal surface exposure (SA) & $\mathrm{cm}^{2} /$ day & 1800 & 5000 \\
\hline Dermal adherence (AF) & $\mathrm{mg} / \mathrm{cm}^{2}$ & 0,2 & 0,2 \\
\hline Dermal adsorption (ABS) & unitless & 0,1 & 0,1 \\
\hline Averaging life span (AT) & year & 70 & 70 \\
\hline Soil dust produce factor (PEF) & $\mathrm{m} / / \mathrm{kg}$ & 1,32 & 1,32 \\
\hline
\end{tabular}

In regulatory terms, an ILCR of $10^{-6}$ or less denotes virtual safety and an ILCR of greater than $10^{-4}$ denotes potentially high risk [11]. Under calculated exposures, the estimated ILCRs for both adult and child are greater than $10^{-4}$. It appeared that the PCBs are pervasive in the sampling areas and cancer risk assessment studies are needed in this sense.

\section{Conclusions}

In this study, it is aimed to compare pollutants that can come from industrial, residential and agricultural areas in comparison with the reference area in the basin where industrial pollution is known to have a very significant impact. Generally increasing PCB values were clearly observed in industrial areas in the study. PCB concentrations reached the highest values for all matrixes in the 2014 Spring and 2015 winter. The increasing values were clearly observed in soil concentrations. The lowest values in terms of averages were observed in pine needle samples. Generally heavier PCB species more abundant in the sampling area. In general, hepta-octa species ( -7 and -8 rings) were predominantly determined for all sampling matrices, 
and the average value of the total PCB concentration was 38\%. It can be said that the concentrations found in industrial areas are heavier species and the light species are dominant in the background concentrations. ILCR were conducted for the observed values in the study. According to the information obtained, "Cancer Increase Rate" due to the PCB concentration was found to be over $10^{-4}$ and cancer risk assessment studies are needed in the area.

Acknowledgement: The present study was supported by TUBITAK (Scientific and

Technological Research Council of Turkey) under Grant Project No:112Y070

\section{REFERENCES}

[1] E. A. Mamontova, E. N. Tarasova, A. A. Mamontov, PCBs and OCPs in human milk in Eastern Siberia, Russia: Levels, temporal trends and infant exposure assessment, CHEMOSPHERE, 178 (2017), 239-248.

[2] Y. Dumanoglu, E. O. Gaga, E. Gungormus, S. C. Sofuoglu, M Odabasi, Spatial and seasonal variations, sources, air-soil exchange, and carcinogenic risk assessment for PAHs and PCBs in air and soil of Kutahya, Turkey, the province of thermal power plants, SCI TOTAL ENVIRON. 580 (2017), 920-935.

[3] P. Torres, R. T. Cunha, C. Micaelo, A. S. Rodrigues, Bioaccumulation of metals and PCBs in Raja clavat, SCI TOTAL ENVIRON. 573 (2016), 1021-1030.

[4] E. Demircioglu, A. Sofuoglu, M. Odabasi, Particle-phase dry deposition and air-soil gas exchange of polycyclic aromatic hydrocarbons (PAHs) in Izmir, Turkey, J HAZARD MATER. 186 (2011), 328-335.

[5] S.C. Chen, C. M. Liao, Health risk assessment on human exposed to environmental polycyclic aromatic hydrocarbons pollution sources, SCI TOTAL ENVIRON. 366 (2006), 112-123.

[6] USEPA, 1991. "Risk Assessment Guidance for Superfund Volume 1, Human Health Evaluation" Manual (Part B, Development of Risk-based Preliminary Remedia- tion Goals). EPA/540/R-92/003 Publication 9285.7-01B. [7] C. Peng, W. Chen, X. Liao, M. Wang, Z. Ouyang, W. Jiao, Y. Bai, Polycyclic aromatic hydrocarbons in urban soils of Beijing: Status, sources, distribution and potential risk, ENVIRON POLLUT, 159 (2011), 802-808.

[8] U.S. EPA (Environmental Protection Agency). 1996. "PCBs: Cancer Dose- Response Assessment and Application to Environmental Mixtures. EPA/600/P-96/001F" http://www.epa.gov/pcb/pubs/pcb.pdf

[9] ATSDR. 2000. "Toxicological profile for polychlorinated biphenyls (update)", Public Health Service, Agency for Toxic substances and Disease registry, Atlanta, US: US Department of Health and Human Services.

[10] J. C. Larsen, Risk assessments of polychlorinated dibenzop-dioxins, polychlorinated dibenzofurans, and dioxin-like polychlorinated biphenyls in food, MOL. NUTR. FOOD RES, 50 (2006), 885-896.

[11] C. M. Liao, K. C. Chiang, Probabilistic risk assessment for personal exposure to carcinogenic polycyclic aromatic hydrocarbons in Taiwanese temples. CHEMOSPHERE, 63(2006), 1610-1619. 